\section{Child abuse and the eye}

\section{Introduction}

Child abuse (non-accidental injury, NAI) affecting the eye may take many forms, but the one most commonly encountered by a paediatric ophthalmologist is that associated with intracerebral injury and results from severe shaking, with or without additional impact injury. Extensive retinal haemorrhage has been regarded as a marker for the 'shaken baby syndrome', but there are still difficult or controversial issues in making this association.

The paediatric ophthalmologist, whether working in a District General or children's hospital, encounters the results of child abuse not infrequently, but its rarity in the population as a whole can make its recognition and management by a non-paediatric specialist or a general ophthalmologist rather difficult.

There are various distinct forms of child abuse, many of which may involve the visual system:
A. Physical abuse
Indirect trauma and shaking
Direct eye trauma
Smothering
Poisoning
B. Induced illness: Munchausen syndrome by proxy
C. Sexual abuse
D. Neglect
E. Emotional abuse

This report was drawn up by the Working Party on the basis of a literature search up to the end of 1997, to address a series of questions that frequently arise in the management of child abuse cases, and that may be discussed in medico-legal proceedings. It is concerned only with the effects on the eye of shaking or indirect trauma to the head, particularly in infants and very young children. Those cases where there has been a direct blow to the eye, or other type of abuse, are not discussed.

The Appendix discusses some of the terms used.

\section{What forces are needed to produce retinal haemorrhages and other signs of intraocular} trauma in infants without direct ocular injury?

There is reliable evidence to show that retinal damage can be produced by severe angular positive or negative acceleration forces alone,
THE OPHTHALMOLOGY CHILD ABUSE WORKING PARTY*

without impact and without direct ocular injury. It has been suggested that this may result from direct vitreous traction on the retina. ${ }^{1}$ The relative additional contribution of an associated sudden rise in intracranial or central venous pressure is uncertain.

Direct evidence that angular acceleration without impact can produce retinal haemorrhages

1. Retinal haemorrhages were produced in adults after emergency aircraft ejection without impact trauma and in experiments in which subjects experienced deceleration above $40 \mathrm{G}$ for fractions of a second. ${ }^{2}$

2. Retinal haemorrhages occurred in children after road traffic accidents in which there had been no direct trauma to the eye, ${ }^{3}$ and they have been described in 'bungee-jumpers'. ${ }^{4-6}$

3. Supportive evidence comes from retinal haemorrhages seen in infants after confessed shaking injuries. ${ }^{3,7}$

\section{Indirect evidence linking brain and eye injury}

Much of the indirect evidence linking brain and eye injury is based on the good correlation between the severity of ocular injury and the severity of the intracerebral injury. This enables information gathered on the forces required for cerebral injury to be extrapolated to eye injury. $1,8,9$

1. Subdural haematomas and other cerebral haemorrhages and tears were produced by whiplash injury without impact in monkeys. This occurred only in subjects that were concussed. The acceleration threshold for injury in humans was predicted to be 6000 radians/s/s or $342000 \mathrm{deg} / \mathrm{s} / \mathrm{s}^{10}$

2. The acceleration threshold for cerebral injury calculated from animal experiments was easily exceeded by shake and impact in lifesized and head-weight-equivalent infant models. ${ }^{11}$ This threshold could not be reached by violent shaking alone but this may have reflected deficiencies in the model construction. ${ }^{3}$

3. Not all infants with retinal haemorrhages associated with abuse have signs of impact injury. ${ }^{1,3,12,13}$
*The members of the working party are: Mr David Taylor, FRCPCH, FRCOphth (Chairman) Dr R. Bonshek, MD, FRCPath Mr D. Brosnahan, FRCOphth Dr N. Carter, MD, FRCPath Mr R.M.L. Doran, FRCOphth Professor G. Dutton, FRCOphth Mr J. Elston, FRCOphth Professor M.A. Green, FRCPath

Miss R.J. Leitch, FRCOphth Mr I.C. Lloyd, FRCOphth Dr Margaret Lynch, MD, FRCPCH

Dr M.A. Parsons, FRCPath Miss I.M. Russell-Eggitt, FRCOphth

$\mathrm{Mr} \mathrm{H}$. Willshaw, FRCOphth Mr G. Woodruff, FRCOphth Mr J.D.H. Young, FRCOphth

Mr David Taylor Eye Department Great Ormond Street Hospital

London WC1N 3JH, UK

Received: 28 April 1998 Accepted in revised form: 26 October 1998 
Other evidence

Retinal haemorrhages were not associated with witnessed accidental trauma unless it had been very severe:

1. One hundred consecutive cases of head injury in children under 2 years were examined for retinal haemorrhages. In 73 of the children the injury was due to a fall, and in 24 it was considered due to NAI. Household falls were neurologically benign, even with skull fractures. Only 10 patients had retinal haemorrhages, of whom 9 were in the 24 child abuse cases; the remaining haemorrhage followed a highspeed road traffic accident. ${ }^{7}$

2. Seventy-nine children under 3 years old had fundus examinations after head injury. Seventy-five of the children had accidental injuries, 1 child had injuries of undetermined cause: they all had normal fundi. All 3 abused children had retinal haemorrhages. ${ }^{14}$

3. Tangential acceleration is associated with much more brain deformation and shear than an equivalent linear acceleration. This may explain the propensity for retinal haemorrhage to occur with shaking injury in infants. ${ }^{7}$

\section{Conclusions}

No absolute values can be given for the angular acceleration forces required to produce retinal bleeding or other injury, but there is good evidence that they must be considerable. Thus, in the absence of direct ocular injury:

1. Retinal haemorrhages are not reported in quite severe household falls, even when associated with skull fractures, but occur after very severe motor accidents. $3,7,15$

2. Retinal haemorrhage is associated with types of cerebral injury that have been shown experimentally to require severe concussive forces.

3. By making comparisons with intracerebral lesions, the finding of retinal haemorrhages with additional features, such as perimacular folds, subretinal haemorrhages, choroidal haemorrhage and vitreous haemorrhage, indicates a greater severity of applied force. $^{1,9}$

\section{Is additional impact necessary for the production of very severe ocular injury?}

Blunt trauma, in addition to angular acceleration, is probably necessary to produce the most serious problems in child abuse, as the deceleration produced in impact injuries is much greater than that produced when the head is flexed or extended to its limits without impact. ${ }^{711}$ Elner et al. ${ }^{16}$ found evidence of head injury at autopsy in all 10 of their cases of suspected child abuse, although the signs were sometimes occult. However, evidence of associated head injury is not always present in severe cerebral injury with coexisting eye injuries. ${ }^{1,12,13,17}$ Gilliland and Folberg ${ }^{3}$ found that, of 80 infants dying of NAI, over half had impact injuries without evidence of shaking, over a third had evidence of combined shaking and impact, and the remaining minority had exclusively shaking-induced injuries.

\section{Conclusion}

Additional impact may contribute to the severity of retinal damage but is not mandatory for its production.

\section{What is the usual site and extent of retinal haemorrhages in child abuse?}

Haemorrhages are seen mostly at the posterior pole; ${ }^{18}$ however, the retinal periphery is often difficult to examine clinically. An autopsy study ${ }^{1}$ demonstrated that subretinal and subhyaloid haemorrhages were more common in the peripheral retina than at the macula or around the optic disc, and least common at the equator, but this pattern has not been assessed in survivors of traumatic episodes. Typically all layers of the retina are involved, ${ }^{1,8,19-23}$ but haemorrhages confined to one layer are also found. ${ }^{22,23}$

Betz et al. ${ }^{24}$ suggested that retinal haemorrhages 'exceeding $20-30 \%$ of the total retinal area cannot be explained by a single traumatic event and must be regarded as a very strong indicator for violent shaking'. Their study, however, did not include controls and lacked some details in the groups studied. ${ }^{25}$ Although it is much more likely that massive retinal haemorrhages are caused by NAI, it cannot be said that less extensive haemorrhages are less likely to be associated with NAI.

\section{Are any ocular fundus findings pathognomonic of child abuse?}

Severe retinal haemorrhage and perimacular folds are frequently seen in NAI, ${ }^{16,18,26,27}$ but they cannot be said to be pathognomonic ${ }^{28}$ as they occur in severe accidental injury and Terson's syndrome. ${ }^{29}$ However, they are much more likely to be seen in child abuse. The presence of perimacular folds may suggest that there have been cycles of acceleration and deceleration, ${ }^{18,27}$ perhaps also with impact. ${ }^{16}$ Haemorrhagic retinal cysts and retinoschisis ${ }^{16,30,31}$ are probably much more frequent in child abuse than in accidental trauma.

\section{Can intraocular haemorrhages increase after the injury?}

It is 'common sense' that retinal haemorrhages will rapidly increase in extent and severity while the trauma and its immediate effects are in progress. However, many of the intracranial events that are associated with retinal haemorrhages do progress gradually: subdural haemorrhages, for instance, may progressively enlarge ${ }^{32}$ and further haemorrhages occur in chronic subdural haemorrhages, at least in adults. ${ }^{33}$ Therefore the finding of increasingly extensive intraocular haemorrhages could reflect observer error, further trauma, further 
haemorrhages as a result of continuation of the effects of the original trauma, or a spread of the haemorrhage from one layer or area of the retina to another, for example from the subhyaloid space into the vitreous.

\section{Can accidental injury cause retinal haemorrhages?}

A number of studies have established that retinal haemorrhages are rare after accidental trauma in infants and young children. ${ }^{15,21,34-38}$ Retinal haemorrhages may be seen after very severe accidental head injury 37,39 causing skull fractures and diffuse or focal intracranial damage; ${ }^{24}$ most of these accidents can be independently corroborated. ${ }^{7}$

In the studies by Buys et al. ${ }^{14}$ and Duhaime et al. ${ }^{7}$ a total of 148 children under 3 years old with accidental injury were specifically examined for retinal haemorrhage; a haemorrhage was found in only one case, a high-speed car accident. The two studies included 58 skull fractures, 40 falls from higher than $1.2 \mathrm{~m}$, many onto hard surfaces, 8 falls down stairs, and $11 \mathrm{car}$ accidents. After excluding the one case of involvement in a high-speed car accident, no child developed retinal haemorrhages. In contrast, retinal haemorrhages were found in 12 of 27 suspected abuse cases When children receive fatal injuries after reportedly short falls, they are more likely to be non-accidental. ${ }^{40}$

\section{Conclusion}

Although retinal haemorrhages may occur after severe accidental head injury, extensive retinal haemorrhages are much more likely to be due to non-accidental than to accidental injury.

\section{For how long can birth-related haemorrhages persist?}

Retinal haemorrhages are common at birth, occurring in between $2.6 \%$ and $59 \%$ of newborn infants. ${ }^{41-44}$ The incidence is increased in prolonged labour, assisted delivery, toxaemia, in the children of older primiparae, and possibly with parenteral vitamin $\mathrm{E}$ and with dinoprostone induction of labour. The incidence appears to be decreased after caesarean section and breech delivery.

There are four usual morphological types of neonatal haemorrhages: superficial retinal (splinter-flame), intraretinal dot/blot/domed, pre-retinal/subhyaloid, and subretinal, which are rare. Birth-related haemorrhages are thought to occur during labour ${ }^{41}$ by leakage from retinal venules and capillaries and they are similar in appearance to haemorrhages occurring after central retinal vein occlusion or raised intracranial pressure. It is suggested ${ }^{41}$ that hypercapnia and hypoxia causes vessel dilatation and compression during labour leads to raised intracranial pressure and impaired venous return, which in turn cause vessel rupture and haemorrhage. There seems to be no association between neonatal retinal haemorrhages and platelet count, plasma fibrinogen level or the Thrombotest result. ${ }^{44}$
Haemorrhages present after birth disappear rapidly with very few exceptions; this has been summarised in table form by von Barsewisch. ${ }^{41}$ The finest nerve fibre layer (NFL) haemorrhages can disappear in $24 \mathrm{~h}$, whilst even extensive NFL haemorrhages are usually gone within a few days. Half of all haemorrhages disappear within $48 \mathrm{~h}^{43}$ and Sezen ${ }^{42}$ found that $2.6 \%$ persisted at 72-120 $\mathrm{h}$ after birth. In one case the haemorrhage persisted for 6 weeks. Larger subhyaloid and larger intraretinal haemorrhages seem to persist for the longest time. ${ }^{44}$ Most neonatal retinal haemorrhages have no visual sequelae, ${ }^{45,46}$ although occasional cases of longterm visual impairment have been reported. ${ }^{47}$

\section{Conclusion}

Neonatal retinal haemorrhages are common. The majority disappear by 8 days but some dome-shaped (sub-internal limiting membrane or subhyaloid) haemorrhages may persist for up to 3 months. Many of the studies were not truly longitudinal and further studies would be helpful.

\section{Is unilateral retinal haemorrhage compatible with child abuse?}

Unilateral retinal haemorrhages are not uncommon with indirect child abuse injuries. This is based on the following evidence:

1. A report of 3 consecutive cases. ${ }^{48}$

2. In 13 autopsy cases, 3 of the 9 in a group with direct head trauma had unilateral retinal haemorrhages. ${ }^{8}$

3. Of 14 consecutive cases of presumed shaken baby, 3 had unilateral retinal haemorrhages. ${ }^{9}$

4. Of 20 cases of shaken infants, 4 had unilateral retinal haemorrhages. ${ }^{49}$

5. In 1 case out of 7 babies with 'physical child abuse' there were haemorrhages on histopathology in only one eye. ${ }^{24}$

Unilateral or highly asymmetrical retinal haemorrhages may also occur in pathological disease states and in accidental trauma. $24,29,50-57$

\section{Conclusion}

Unilateral retinal haemorrhages can occur in both direct and indirect child abuse injuries and in other pathological processes.

\section{Is intracranial damage always accompanied by retinal haemorrhages?}

There is a close correlation between the severity of retinal haemorrhages and intracranial injuries, ${ }^{1,9,58}$ although it is sometimes difficult to estimate the severity of or even to diagnose intracranial injury on the initial CT scan. ${ }^{59}$ It is usual for NAI patients with subdural haemorrhages and other intracranial injuries to have retinal haemorrhages, 
but the association is not invariable; ${ }^{1}$ between $11 \%{ }^{38}$ and $39 \%$ of abused children do not have retinal haemorrhages.

\section{Can a bleeding diathesis or blood dyscrasia cause retinal haemorrhages similar to those seen in child abuse?}

Gayle et al..$^{50}$ have said that it is necessary to exclude a bleeding diathesis in children with suspected child abuse. However, retinal haemorrhages are probably rare even in children with abnormal bleeding studies, although there is a need for studies to confirm this. Intracranial haemorrhage is infrequent after accidental head trauma in children with a congenital coagulopathy. ${ }^{61}$ The retinal haemorrhages seen in leukaemia sometimes cannot reliably be distinguished funduscopically from those of NAI, but they are distinguished by the abnormal leukocyte counts and thrombocytopenia, ${ }^{62}$ which can prevent the misdiagnosis of NAI. ${ }^{63}$ Extensive retinal haemorrhages have been described in two teenagers with von Willebrand's disease, ${ }^{64}$ a common and variable disorder. Vitreous and subarachnoid haemorrhages are described in severe protein $C$ deficiency with disseminated intravascular coagulation. ${ }^{65,66}$ Evidence of a bleeding disorder is not uncommon in child abuse and the two conditions are not mutually exclusive. ${ }^{67,68}$ Advice from a haematologist or other specialist may be necessary in this situation.

\section{What other conditions of childhood may have retinal haemorrhages?}

Retinal haemorrhage can also be associated with the following conditions of childhood:

1. Leukaemia. Ten per cent of children with acute lymphatic leukaemia have intraretinal haemorrhages and $3 \%$ have white centred haemorrhages. The leukocyte count is substantially abnormal in all cases and most affected children are thrombocytopenic. ${ }^{62}$ Not all leukaemic children with retinal haemorrhages, however, have other abnormal blood parameters. ${ }^{69}$ A 4-week-old infant with myelogenous leukaemia and neurofibromatosis presented with a high fever that was initially suspected to be caused by child abuse. ${ }^{63}$

2. Haemorrhagic disease of the newborn. There appears to be no association between the Thrombotest results and birth-related intraocular haemorrhages; ${ }^{44}$ this had been suggested in $1941 .^{70}$

3. Retinopathy of prematurity (ROP). ROP can be differentiated by the associated findings.

4. Sickle cell retinopathy. ${ }^{71}$ Sickle cell retinopathy can be differentiated by haematological studies and the presence of new vessels.

5. ECMO treatment. Although some patients having extracorporeal membrane oxygenation (ECMO) have intraretinal haemorrhages and other changes, ${ }^{54,55,72,73}$ they are not necessarily related to the ECMO itself and are insufficiently serious or frequent to necessitate screening of ECMO patients. $^{74,75}$

6. Galactosaemia. Vitreous haemorrhages have been described in severely affected children. ${ }^{76}$

7. Henoch-Schönlein purpura. Transient punctate retinal haemorrhages were described in 4 of 22 children aged 8 months to 14 years. ${ }^{77}$ Resolving haemorrhages may appear ophthalmoscopically like vitelliform lesions. $^{78}$

8. Maternal ingestion of cocaine. Birth-trauma-like haemorrhages that last longer than normal have been described in neonates born to cocaine addicts. ${ }^{79}$ In

- addition, these children are at high risk of NAI.

9. Meningitis. Retinal haemorrhages have been associated with meningococcal meningitis. ${ }^{50}$

10. Intracranial vascular malformation. Spontaneous subhyaloid and retinal haemorrhages occurred in an infant with an intracranial arterial aneurysm, ${ }^{80}$ and an optic sheath haemorrhage was described in a child with a ruptured subarachnoid malformation. ${ }^{52}$ In both cases NAI had been suspected.

11. Optic disc drusen, tuberous sclerosis ${ }^{81}$ and X-linked retinoschisis. ${ }^{82}$ Vitreous haemorrhage has been recorded with these conditions.

12. Intracranial pathology. Chronic, severe papilloedema associated with diagnosable intracranial pathology may cause peripapillary haemorrhages and acute, severely raised intracranial pressure may cause widespread haemorrhage.

13. Intraocular surgery. Multiple retinal haemorrhages commonly occur following intraocular surgery in infants. ${ }^{83,84}$

14. Severe hypertension. Retinal haemorrhages are often present in children with severe hypertension.

\section{Conclusion}

Most conditions of childhood that cause retinal haemorrhages have distinguishing clinical features and further investigations are indicated only when they are clinically appropriate; a 'battery' of tests for all cases is not appropriate.

\section{Can seizures cause retinal haemorrhages?}

In adults with seizures retinal haemorrhages were not noted in any of 560 visits to an emergency department that resulted in 7 deaths and 553 injuries. ${ }^{85} \mathrm{~A}$ case of extensive retinal haemorrhages was described in a 32-year-old man after status epilepticus 3 months after surgery for Arnold Chiari malformation. ${ }^{86}$

A study in which 33 children, not including any neonates, were examined ophthalmoscopically within $48 \mathrm{~h}$ of hospital admission for an episode of seizures of various types revealed no retinal haemorrhages despite some of the children having vomited or having had cardiopulmonary resuscitation; ${ }^{51}$ after this study was completed the authors reported a case of a premature infant who had seizures from 10 days and was found to 
have unilateral retinal haemorrhages at 23 days. A study from the same hospital ${ }^{87}$ suggested that the upper limit of the $95 \%$ confidence interval of retinal haemorrhages, following convulsions in children under 14 years old, is less than $5 / 100$.

\section{Conclusion}

Convulsions in young children rarely, if ever, cause retinal haemorrhages.

\section{Can cardio-pulmonary resuscitation (CPR) cause retinal haemorrhages?}

Closed chest cardiac massage, even by trained doctors, causes a marked rise in intracranial pressure. ${ }^{88}$ Violent chest compression in child abuse may cause retinal haemorrhages. ${ }^{89-91}$ Attempted CPR by untrained individuals has been advanced as an innocent cause of retinal haemorrhages in a single case report, ${ }^{92}$ although NAI was not convincingly excluded.

There have been other reports of retinal haemorrhages occurring after CPR without other explanation for the haemorrhages. ${ }^{56,93}$ One neonate with meconium aspiration who had CPR during the first day of life before being put onto ECMO suffered seizures, and vitreous haemorrhages were noted on the 11th day. ${ }^{55}$ Gilliland and Luckenbach ${ }^{94}$ found no case of retinal haemorrhage in their autopsy study of 169 cases, 131 of which had had prolonged resuscitation.

Kanter $^{89}$ found retinal haemorrhages on nonmydriatic ophthalmoscopy in only 1 of 45 children who had not had prior trauma, and were successfully or unsuccessfully resuscitated: that child had severe arterial hypertension and seizures. Of 9 trauma victims, 5 had retinal haemorrhages; 4 of these were correctly suspected as being due to child abuse and the other had had head and chest injuries in an automobile accident. Kanter could not examine a further 5 children who had corneal clouding or miosis. He concluded that 'When retinal hemorrhage is detected in the pediatric patient after CPR, prior trauma should be assumed ... Retinal hemorrhage should not be attributed to the mechanical effects of CPR'.

Experimental evidence from studies on piglets showed no retinal haemorrhages despite high, monitored, intracranial and intrathoracic pressure. ${ }^{95}$

\section{Conclusion}

CPR alone is very unlikely to cause retinal haemorrhages, even if carried out by unskilled individuals.

\section{Can prolonged vomiting, gagging, etc., cause retinal haemorrhage?}

Various causes of Valsalva's manoeuvre may be associated with retinal haemorrhage in adults, ${ }^{96}$ but with the possible exception of pertussis, no cases have been described in children.

\section{Are retinal haemorrhages in child abuse more common} in infants than in older children?

The answer to the above question is unequivocally 'Yes'. Retinal haemorrhages are more frequently described in NAI below 1 year of age $\mathrm{e}^{17,22}$ and they become less frequent and less severe in older children.

Is it possible to determine, from an examination of the retina, the time at which an injury occurred or whether there have been haemorrhages at more than one time?

Skin bruises may show changes with time that allow approximate dating of the injury. ${ }^{97}$ In the eye, however, the colour changes that occur in skin bruising are absent, the changes are so gradual, and the retinal background contrast so variable, that accurate dating of retinal haemorrhages to within days, based on their ophthalmoscopic appearance, is not possible. The colour of a retinal haemorrhage is influenced at least as much by its size as by its age. Brown-yellow ochre membranes are consistent with injuries at least 1 month old, and the presence of bright red fresh haemorrhage together with ochre membranes strongly suggests haemorrhages of different ages. After a few days an eye with a severe intraocular haemorrhage takes on a greenish hue on slitlamp or ophthalmoscopic examination.

Mild retinal haemorrhages in NAI probably clear rapidly; 'flame-shaped' birth-related haemorrhages may resolve within 24 hours; ${ }^{42,44}$ moderately severe retinal haemorrhages clear within a few weeks; ${ }^{98}$ but severe, widespread retinal and vitreous haemorrhages may take many months to clear, and usually are associated with substantial residual damage. ${ }^{99,100}$ If subretinal and intraretinal haemorrhages are found in the absence of flame-shaped haemorrhages this may suggest that the injury occurred at least $24 \mathrm{~h}$ previously, but there are no studies to corroborate this.

Pathological studies suggest that the finding of haemosiderin in a haemorrhage indicates it is more than about 3 days old, ${ }^{101}$ although in current forensic practice it is generally agreed that haemosiderin begins to appear around $48 \mathrm{~h}$ after injury in bruises in skin and subcutaneous tissue. If there are some haemorrhages with and some without haemosiderin this suggests that the haemorrhages are of different ages, ${ }^{16,102}$ but it is possible that there are minor differences in the biochemical ageing of haemorrhages at different sites or even within a single organ. There is no detailed research giving the time of appearance of haemosiderin in retinal tissues.

The persistence of haemosiderin following birthrelated haemorrhage at any site is also poorly documented; current opinion favours its disappearance from soft tissues within 6-8 weeks after birth. Xanthochromic staining of the relatively avascular dura may persist for much longer. If haemosiderin is found in 
the relatively vascular eye tissues in infants of more than 2-3 months old it is likely that this is from a haemorrhage occurring after birth.

\section{Epilogue}

Child abuse, and its effects on the eye and brain, results in a complex interplay of social, legal, clinical, biomechanical and pathological factors. Much of this article has been devoted to trying to answer clinical, pathological and biochemical questions that affect the clinical management and the legal process: it is clear that a number of the answers are not black and white, but sufficiently grey to warrant the confirmation of some existing studies, and the urgent institution of new evidence-based studies to clarify outstanding questions. The ultimate way forward, however, lies along a different route: that of understanding the social pathogenesis and treating the real underlying causes.

While this report confirms that considerable force is required to produce a retinal or brain injury, even if a shaking injury is non-accidental this does not necessarily imply that the resulting injuries are the effect intended by the assailant. There may be further need for campaigns that draw parents' and other carers' attention to the fact that the effects of shaking may be more severe than expected. ${ }^{103,104}$

\section{Appendix. Definitions}

Child abuse is a general term used to cover the various forms of damage inflicted on children, including neglect, sexual abuse, emotional abuse, induced illness and physical injury. Although this article concentrates on aspects of physical abuse, it is acknowledged that a child may have been subject to more than one kind of abuse. Non-accidental injury is a term that, whilst it is most frequently used in the child abuse context, strictly encompasses other forms of injury including some sports, criminal injury or surgery.

A number of terms are used in the literature to describe various forms of acceleration:

Positive acceleration ('acceleration') results in an increase in speed.

Negative acceleration ('deceleration') results in a decrease in speed.

Linear acceleration (positive or negative) is acceleration in a straight line and is measured in distance/s/s. Angular or rotational acceleration is acceleration in a plane about an axis: it is measured in units of angle (degrees or radians)/s/s. It is, in the child abuse context, usually a compound of acceleration in three planes: the sagittal plane, about an axis passing roughly between the ears ('pitch'); the axial or horizontal plane, about an axis between the jaw and the top of the head ('yaw'); and the coronal plane, about an axis from the nose to the occiput ('tilt').
Tangential acceleration is the linear acceleration, measured in distance/s/s, perpendicular to the radius of a circle; it results in shear forces that depend on the radius of the circle, the weight of the object, and the rate of acceleration.

Jerk is the term used for the rate of change of acceleration and is measured in distance/s/s/s.

\section{References}

1. Green MA, Lieberman G, Milroy CM, Parsons MA. Ocular and cerebral trauma in non-accidental injury in infancy: underlying mechanisms and implications for paediatric practice. Br J Ophthalmol 1996;80:282-7.

2. Lyle DJ, Stapp JP, Button RR. Ophthalmologic hydrostatic pressure syndrome. Am J Ophthalmol 1957;44:652-7.

3. Gilliland MG, Folberg R. Shaken babies: some have no impact injuries. J Forensic Sci 1996;41:114-6.

4. David DB, Mears T, Quinlan MP. Ocular complications of bungee jumping. Br J Ophthalmol 1994;78:234-5.

5. Jain BK, Talbot EM. Bungee jumping and intraocular haemorrhage. Br J Ophthalmol 1997;78:236-7.

6. Chan J. Ophthalmic complications of bungee jumping. Br J Ophthalmol 1994;78:239.

7. Duhaime AC, Alario AJ, Lewander WJ, Schut L, Sutton LN, Seidl TS, et al. Head injury in very young children: mechanisms, injury types and ophthalmologic findings in 100 hospitalised patients younger than two years of age. Pediatrics 1992;90:179-85.

8. Budenz DL, Farger MG, Mirchandani HG, Park H, Rorke LB. Ocular and optic nerve hemorrhages in abused infants with intracranial injuries. Ophthalmology 1994;101:559-65.

9. Wilkinson WS, Han DP, Rappley MD, Owings CL. Retinal hemorrhage predicts neurologic injury in the shaken baby syndrome. Arch Ophthalmol 1989;107:1472-4.

10. Ommaya AK, Faas F, Yarnell P. Whiplash injury and brain damage: an experimental study. JAMA 1968;204:285-9.

11. Duhaime AC, Gennarelli TA, Thibault LE, Bruce DA, Margulies SS, Wiser R. The shaken baby syndrome: a clinical, pathological and biomechanical study. J Neurosurg 1987;66:409-15.

12. Hadley MN, Murphy A, Rekate HL, Sonntag V. The infant whiplash-shake injury syndrome: a clinical and pathological study. Neurosurgery 1989;24:536-40.

13. Guthkelch AN. Infantile subdural haematoma and its relationship to whiplash injuries. BMJ 1971;2:430-1.

14: Buys YM, Levin AV, Enzenauer RW, Elder JE, Letourneau MA, Humphreys RP, et al. Retinal findings after head trauma in infants and young children. Ophthalmology 1992;99:1718-23.

15. Reiber GD. Fatal falls in childhood. How far must children fall to sustain fatal head injury? Report of cases and review of the literature. Am J Forensic Med Pathol 1993;14:201-7.

16. Elner SG, Elner VM, Arnall M, Albert DM. Ocular and associated systemic findings in suspected child abuse. Arch Ophthalmol 1990;108:1094-101.

17. Frank $Y$, Zimmerman $R$, Leeds NMD. Neurological manifestations in abused children who have been shaken. Dev Med Child Neurol 1985;27:312-5.

18. Munger CE, Peiffer RL, Bouldin TW, Kylstra JA, Thompson RL. Ocular and associated neuropathologic observations in suspected whiplash baby syndrome: a retrospective study of 12 cases. Am J Forensic Med Pathol 1993;14:193-200.

19. Jensen AD, Smith RE, Olson MI. Ocular clues to child abuse. J Pediatr Ophthalmol 1971;8:270-2.

20. Mushin A, Morgan G. Ocular injury in the battered baby. Br J Ophthalmol 1971;55:343-7. 
21. Rao N, Smith RE, Choi JH, Xiaohu X, Kornblum RN. Autopsy findings in the eyes of fourteen fatally abused children. Forensic Sci Int 1988;36:293-9.

22. Riffenburgh RS, Sathyavagiswaran L. The eyes of child abuse victims; autopsy findings. J Forensic Sci 1991;36:293-9.

23. Riffenburgh RS, Sathyavagiswaran L. Ocular findings at autopsy of child abuse victims. Ophthalmology 1991;98:1519-24.

24. Betz P, Eisenmenger W, Lignitz E, Miltner E, Puschel K. Morphometrical analysis of retinal hemorrhages in the shaken baby syndrome. Forensic Sci Int 1996;78:71-80.

25. James DS, Leadbetter S. Letter to the editor. Forensic Sci Int 1996;82:255

26. Gaynon MW, Koh K, Marmor MF, Frankel LR. Retinal folds in the shaken baby syndrome. Am J Ophthalmol 1988;106:423-5.

27. Massicotte SJ, Folberg R, Torczynski E, Gilliland MGF, Luckenbach MW. Vitreoretinal traction and perimacular retinal folds in the eyes of deliberately traumatized children. Ophthalmology 1991;98:1124-7.

28. Tongue AC. The ophthalmologist's role in diagnosing child abuse. Ophthalmology 1991;98:1009-11.

29. Keithahn MAZ, Bennett SR, Cameron D, Mieler WF. Retinal folds in terson syndrome. Ophthalmology 1993;100:1187-90.

30. Greenwald MJ, Weiss A, Oesterle CS, Friendly DS. Traumatic retinoschisis in battered babies. Ophthalmology 1986;93:618-25.

31. Morris R, Kuhn F, Witherspoon CD. Hemorrhagic macular cysts [letter]. Ophthalmology 1994;101:1.

32. Till K. Subdural haematoma and effusion in infancy. BMJ 1968;3:400-2.

33. Hashimoto N, Sakakibara T, Yamamoto K. Two fluid-blood density levels in chronic subdural hematoma. J Neurosurg 1992;77:310-11.

34. Elder JE, Taylor RG, Klug GL. Retinal haemorrhage in accidental head trauma in childhood. J Paediatr Child Health 1991;27:286.

35. Alario A, Duhaime A, Lewander W, Tsirias W, Wallach M, O'Shea J. Do retinal haemorrhages occur with accidental head trauma in young children? [abstract] Am J Dis Child 1990;144:445.

36. Eisenbrey AB. Retinal haemorrhage in the battered child. Childs Brain 1979;5:40-4.

37. Johnson DL, Braun D, Friendly D. Accidental head trauma and retinal hemorrhage. Neurosurgery 1993;33:231-5.

38. Billmire ME, Myers PA. Serious head injury in infants: accident or abuse? Pediatrics 1985;75:340-2.

39. Gilliland MGF, Luckenbach MW, Chenier TC. Systemic and ocular findings in 169 prospectively studied child deaths: retinal hemorrhages usually mean child abuse. Forensic Sci 1994;68:117-32.

40. Chadwick DL, Chin S, Salerno C, Landsverk J, Kitchen L. Deaths from falls in children: how far is fatal? J Trauma 1991;31:1353.

41. Von Barsewisch B. Perinatal retinal haemorrhages: morphology, aetiology and significance. Berlin: SpringerVerlag, 1979.

42. Sezen F. Retinal haemorrhages in newborn infants. Br J Ophthalmol 1970;55:248-53.

43. Giles CL. Retinal haemorrhages in the newborn. Am J Ophthalmol 1960;49:1005-10.

44. Baum JD, Bulpitt CJ. Retinal and conjunctival haemorrhage in the newborn. Arch Dis Child 1970;45:344-9.

45. Bonamour G. Le prognostic eloigne des hemorrhagies retiniennes du nouveau-né. Bull Soc Fr Ophtalmol 1949;62:227-36.

46. Von Noorden GK, Khodahoust A. Retinal haemorrhage in newborns and organic amblyopia. Ann Ophthalmol 1973;89:91-3.
47. Zwaan J, Cardenas R, O'Connor PS. Long-term outcome of neonatal macular haemorrhage. Pediatr Ophthalmol Strabismus 1997;34:286-8.

48. Tyagi AK, Willshaw HE, Ainsworth JR. Unilateral retinal haemorrhages in non-accidental injury. Lancet 1997;349:1224

49. Ludwig S, Warman M. Shaken baby syndrome: a review of 20 cases. Ann Emerg Med 1984;13:104-7.

50. Fraser SG. Retinal haemorrhage in meningitis [letter]. Eye 1995;9:659-60.

51. Sandramouli S, Robinson R, Tsaloumas M, Willshaw HE. Retinal haemorrhages and convulsions. Arch Dis Child 1997;76:449-51.

52. Weissgold DJ, Budenz DL, Hood I, Rorke LB. Ruptured vascular malformation masquerading as battered/shaken baby syndrome: a nearly tragic mistake. Surv Ophthalmol 1995;39:509-12.

53. Burton TC. Unilateral Purtscher's retinopathy. Ophthalmology 1980;87:1096-105.

54. Sethi SK. Retinal hemorrhages after extracorporeal membranous oxygenation. North Carolina Med J 1990;51:246.

55. Carney MD, Wortham E, Al-Mateen KB. Vitreous hemorrhage and extracorporeal membrane oxygenation. Am J Ophthalmol 1993;115:391-3.

56. Goetting MG, Sowa B. Retinal hemorrhage after cardiopulmonary resuscitation in children: an etiologic reevaluation. Pediatrics 1990;85:585-8.

57. Kelley JS. Purtscher's retinopathy related to chest compression by safety belts. Am J Ophthalmol 1972;74:278-83.

58. Zimmerman RA, Bilianuk LT, Bruce D, Schut L, Uzzell B, Goldberg H. Interhemispheric acute subdural hematoma: a computed tomographic manifestation of child abuse. Neuroradiology 1978;16:39-40.

59. Giangiacomo J, Khan JA, Levine C, Thompson VM. Sequential cranial computed tomography in infants with retinal hemorrhages. Ophthalmology 1988;95:295-9.

60. Gayle MO, Hered RW, Harwood-Nuss A, Kissoon N. Retinal hemorrhage in the young child: a review of etiology, predisposed conditions, and clinical implications. J Emerg Med 1995;13:233-9.

61. Dietrich AM, James CD, King DR. Head trauma in children with congenital coagulation disorders. J Pediatr Surg 1994;29:28-32.

62. Guyer DR, Schachat AP, Vitale S, Markowitz JA, Braine H, Burke PJ, et al. Relationship between fundus lesions and hematologic parameters at diagnosis. Ophthalmology 1989;96:860-4.

63. Shaw NJ, Eden OB. Juvenile chronic myelogenous leukemia and neurofibromatosis in infancy presenting as ocular hemorrhage. Pediatr Hematol Oncol 1989;6:23-6.

64. Shiono T, Abe S, Watabe T, Noro M, Tamai M, Akutso Y, et al. Vitreous, retinal and subretinal haemorrhages associated with von Willebrand's syndrome. Graefes Arch Clin Exp Ophthalmol 1992;230:496-7.

65. Pulido JS, Lingua RW, Cristol BS, Byrne SF. Protein C deficiency associated with vitreous hemorrhage in a neonate. Am J Ophthalmol 1987;104:546-7.

66. Cassels-Brown A, Minford AMB, Chatfield SL, Bradbury JA. Ophthalmic manifestations of neonatal protein $C$ deficiency. Br J Ophthalmol 1994;78:486-7.

67. O'Hare AE, Eden OB. Bleeding disorders and nonaccidental injury. Arch Dis Child 1984;59:860-4.

68. Hymel KP, Abshire TC, Luckey DW, Jenny C. Coagulopathy in pediatric abusive head trauma. Pediatrics 1997;99:371-5.

69. Robb RM, Ervin LD, Sallan SE. A pathological study of eye involvement in acute leukemia of childhood. Trans Am Acad Ophthalmol Otolaryngol 1978;76:90-101. 
70. Maumenee AE, Hellman LM, Shettles LB. Factors influencing plasma prothrombin in the newborn infant: the effect of antenatal administration of vitamin $K$ on the incidence of retinal hemorrhage in the newborn. Bull Johns Hopkins Hosp 1941;68:158-61.

71. Luxenberg MN. The evolution of salmon-patch hemorrhages in sickle cell retinopathy. Arch Ophthalmol 1989;107:1814-5.

72. Young TL, Quinn GE, Baumgart S, Schaffer DB. Extracorporeal membrane oxygenation causing unilateral retinal vasculopathy in neonates. Ophthalmology 1992;99(Suppl):149.

73. Patrias MC, Rabinowicz IM, Klein MD. Ocular findings in infants treated with extracorporeal membrane oxygenator support. Pediatrics 1988;82:560-4.

74. Varn MM, Donahue ML, Saunders RA, Baker JD, Smith $\mathrm{CM}$,Wilson ME. Retinal examinations in infants after extracorporeal membrane oxygenation. J Pediatr Ophthalmol Strabismus 1997;34:182-5.

75. Pollack JS, Tychsen L. Prevalence of retinal hemorrhages in infants after extracorporeal membrane oxygenation. Am J Ophthalmol 1996;121:297-303.

76. Levy HL, Brown AE, Williams SE, de Juan E. Vitreous hemorrhage as an ophthalmic complication of galactosemia. J Pediatr 1996;129:922-5.

77. Petersen S, Taaning E, Söderström T, Pilgaard B, Traenebjaerg L, Christensen $\mathrm{T}$, et al. Immunoglobulin and complement studies in children with Schönlein-Henoch syndrome and other vasculitic diseases. Acta Paediatr Scand 1991;80:1037-43.

78. Raja SC, Fekrat S, Connor TB. Bilateral macular vitelliform lesions in a thrombocytopenic patient [case report]. Arch Ophthalmol 1995;113:411-3.

79. Silva-Araujo. Maternal ingestion of cocaine. Retina 1996;16:411-8.

80. Mclellan NJ, Prasad R, Punt J. Spontaneous subhyaloid and retinal hemorrhages in an infant. Arch Dis Child 1986;61:1130-2.

81. Atkinson A, Sanders MS, Wong V. Vitreous haemorrhage in tuberous sclerosis. Br J Ophthalmol 1973;57:773-9.

82. George NDL, Yates JRW, Bradshaw K, Moore AT. Infantile presentation of X-linked retinoschisis. Br J Ophthalmol 1995;79:653-7.

83. Christiansen S, Munoz M, Capo H. Retinal haemorrhage following lensectomy and vitrectomy in children. J Pediatr Ophthalmol Strabismus 1993;30:24-7.

84. Mets M, Del Monte M. Hemorrhagic retinopathy following childhood cataract extraction [letter] Arch Ophthalmol 1986;104:975-9.

85. Kirby S, Sadler RM. Injury and death as a result of seizures. Epilepsia 1995;36:25-8.

86. Feyi-Waboso AC, Beck L. Minerva column. BMJ 1997;314:688.
87. Tyagi AK, Scotcher S, Kozeis N, Willshaw H. Can convulsions alone cause retinal haemorrhages in infants? $\mathrm{Br}$ J Ophthalmol 1998;82:659-60.

88. Rogers MC, Nugent SK, Stidham GL. Effects of closed chest cardiac massage on intracranial pressure. Crit Care Med 1979;7:454-6.

89. Kanter RK. Retinal hemorrhages after cardiopulmonary resuscitation or child abuse. J Pediatr 1986;108:430-2.

90. Tomasi LG, Rosman NP. Purtscher retinopathy in the battered child syndrome. Am J Dis Child 1975;129:1335-7.

91. Carter J, McCormick AQ. Whiplash shaking syndrome: retinal hemorrhages and computerised axial tomography of the brain. Child Abuse Neglect 1983;7:279-86.

92. Bacon CJ, Sayer GC., Howe J. Extensive retinal haemorrhages in infancy: an innocent cause. BMJ 1978;1:281.

93. Weedn VVW, Mansour AM, Nichols MM. Retinal hemorrhage in an infant after cardiopulmonary resuscitation. Am J Forensic Pathol 1990;11:79-82.

94. Gilliland MGF, Luckenbach MW. Are retinal hemorrhages found after resuscitation attempts? Am J Forensic Med Pathol 1993;14:187-92.

95. Fackler JC, Berkovitz ID, Green WR. Retinal hemorrhages in newborn piglets following cardiopulmonary resuscitation. Am J Dis Child 1992;146:1294-6.

96. Duane TD. Valsalva hemorrhagic retinopathy. Trans Am Ophthalmol Soc 1972;70:298-313.

97. Stephenson T. Ageing of bruising in children. R Soc Med 1997;90:312-4.

98. Giangiacomo J, Barkett KJ. Ophthalmoscopic findings in occult child abuse. J Pediatr Ophthalmol Strabismus 1985;22:234-7.

99. Matthews GP, Das A. Dense vitreous hemorrhages predict poor visual and neurological prognosis in infants with shaken baby syndrome. J Pediatr Ophthalmol Strabismus 1996;33:260-5.

100. Ferrone PJ, de Juan E. Vitreous hemorrhage in infants. Arch Ophthalmol 1994;112:1185-9.

101. Gilliland MGF, Luckenbach MW, Massicotte SJ, Folberg R. The medicolegal implications of detecting hemosiderin in the eyes of children who are suspected of being abused [letter]. Arch Ophthalmol 1991;109:321-2.

102. Elner SG, Elner VM, Albert DM, Arnall M. The medicolegal implications of detecting hemosiderin in the eyes of children who are suspected of being abused [reply to letter from Gilliland et al.] Arch Ophthalmol 1991;109:322.

103. Carty H, Ratcliffe J. The shaken baby syndrome. Parents and other carers need to known of its dangers. BMJ 1995;310:344-5.

104. Showers J. 'Don't shake the baby': the effectiveness of a prevention programme. Child Abuse Neglect 1992;16:11-8. 